\title{
Efficacy of chemomechanical caries removal in reducing cariogenic microbiota: a randomized clinical trial
}

\section{Michelle Mikhael AMMARI ${ }^{(a)}$ Luiz Flávio Martins MOLITERNO(b) Raphael HIRATA JÚNIOR(c) Mariana Canano SÉLLOS(d) Vera Mendes SOVIERO'(b) Wagner Pereira COUTINHO FILHO(e) $^{(2)}$}

(a)Department of Specific Training, School of Dentistry, Universidade Federal Fluminense - UFF, Nova Friburgo, RJ, Brazil.

(b) Department of Preventive and Community Dentistry, School of Dentistry, Universidade do Estado do Rio de Janeiro - UERJ, Rio de Janeiro, RJ, Brazil.

(c)Department of Microbiology, Immunology and Parasitology, School of Medicine, Universidade do Estado do Rio de Janeiro UERJ, Rio de Janeiro, RJ, Brazil.

(d) School of Dentistry, Universidade do Estado do Rio de Janeiro - UERJ, Rio de Janeiro, RJ, Brazil.

(e)Department of Microbiology, School of Dentistry, Centro Universitário Serra dos Órgãos - UNIFESO, Teresópolis, RJ, Brazil.

Declaration of Interests: The authors certify that they have no commercial or associative interest that represents a conflict of interest in connection with the manuscript.

Corresponding Author:

Michelle Mikhael Ammari

E-mail:miammari@hotmail.com

DOI: 10.1590/1807-3107BOR-2014.vol28.0031 Epub XXXXX, 2014

Submitted: Nov 14, 2012

Accepted for publication: Mar 20, 2014

Last revision: Jul 14, 2014

\begin{abstract}
The aim of this study was to compare the efficacy of chemochemical methods (Carisolv ${ }^{\mathrm{TM}}$ and Papacárie ${ }^{\circledR}$ ) versus the manual method (excavators) in reducing the cariogenic microbiota in dentine caries of primary teeth. Forty-six healthy children (5 to 9 years old) having at least one primary tooth with a cavitated dentine carious lesion were included in the study. The teeth presented no clinical or radiographic signs of pulpal involvement. The sample of 74 teeth was randomly divided into three different groups: Papacárie ${ }^{\circledR}(n=25)$, Ca$\operatorname{risolv}^{\mathrm{TM}}(\mathrm{n}=27)$ and Manual $(\mathrm{n}=22)$. Samples of carious and sound dentine were collected with sterile excavators before and after caries removal in the three groups. The dentine samples were transferred to glass tubes containing a $1 \mathrm{~mL}$ thioglycollate medium used as a carrier and enriched for microbiological detection of mutans streptococci and Lactobacillus spp, after incubation for $6 \mathrm{~h}$ at room temperature. The minimum detection value for colony forming units (CFU) was $3.3 \times 102 \mathrm{CFU} / \mathrm{ml}$, and the results were converted into scores from 0 to 4 . A significant difference was observed in relation to the microbiological scores before and after caries removal for all methods (Wilcoxon test; $p<0.001$ ). The use of chemomechanical methods for caries removal did not improve the reduction of cariogenic microorganisms in dentine caries lesions, in comparison with manual excavation.
\end{abstract}

Keywords: Dental Caries; Papain; Microbiology; Tooth, Deciduous.

\section{Introduction}

The therapeutic approach to carious dentine lesions has been reconsidered by the scientific community over time as a way to preserve as much tooth structure as possible, increase the longevity of teeth and prevent the repetitive restorative cycle. ${ }^{1,2,3}$ Based on the minimal invasive dentistry concept, more conservative approaches have been recommended ${ }^{4,5}$ such as partial caries removal, ${ }^{6}$ atraumatic restorative treatment $^{7}$ and chemomechanical methods, ${ }^{8,9}$ instead of conventional caries removal by drilling and manual excavation.

Although the chemomechanical system was developed over 30 years ago, it only started to gain attention in the late 90s, when Carisolv ${ }^{\mathrm{TM}}$ was released on the market and began to be used widely. This system involves application of a gel composed of an amino acid solution and sodium hypochlorite, which are able to dissolve collagen fibers degraded 
by caries, facilitating their removal by appropriated manual instruments. ${ }^{8,10}$ In order to disseminate the large-scale use of the chemomechanical method to remove carious dentine, and considering the high cost of Carisolv ${ }^{\mathrm{TM}}$, a proteolytic gel named Papacárie $^{\circledR}$ was released in Brazil. Papacárie ${ }^{\circledR}$ combines the collagen degradation effect of papain (a natural protease) and the bactericide effect of chloramines.,11

A certain number of residual microorganisms, $10^{1}$ to $10^{3}$ of colony forming units (CFU), in the dentine after cavity preparation is considered acceptable and not harmful to teeth. ${ }^{12,13,14}$ Clinical research comparing the conventional method (drilling) with the Carisolv ${ }^{\mathrm{TM}}$ chemomechanical method has concluded that both methods are similar in terms of CFU reduction in residual dentine. ${ }^{13,14,15,16}$

The purpose of the present study was to compare the efficacy of the chemochemical methods (Carisolv $^{\mathrm{TM}}$ and Papacárie ${ }^{\circledR}$ ) versus the manual method (excavators) in reducing the cariogenic microbiota in dentine caries of primary teeth.

\section{Methodology}

Study design: This study was designed as a randomized, controlled clinical trial following the CONSORT statement $t^{17}$. Three hundred and eight children (5 to 9 years old) were screened at the Pediatric Dental Clinic of Universidade Estadual do Rio de Janeiro. Children who presented at least one tooth with dentine caries accessible (cavitated) for excavation in the occlusal or buccal surfaces were considered eligible for the study. Informed consent was obtained from parents and the study was approved by the Research Ethics Committee (1007-CEP-HUPE) at the Universidade Estadual do Rio de Janeiro (UERJ). An experienced clinician detected carious lesions visually and in radiographs. Bite-wing radiographs were used to assess the depth of the occlusal lesions. All radiographs were performed using pediatric film-holders (Indusbello ${ }^{\circledR}$, Londrina, Brazil). Dental examinations were carried out in a dental chair under standardized conditions after prophylaxis.

Forty-eight children (mean age of 6 to 9 years) were included in the study and 95 primary teeth with dentine carious lesions accessible for excavation were selected. Twenty-one teeth were excluded due to extensive lesion depth (in the inner third of the dentine) or due to clinical or radiographic signs of pulpal involvement. The final sample (74 primary teeth, 40 anterior teeth with buccal caries lesion and 34 posterior teeth with occlusal lesions) was randomly allocated to one of the three methods using a random numbers table. When more than one tooth was selected in the same child, the teeth were included in the table following the examination sequence from the upper right to the lower right quadrants. After randomization, the final sample was allocated as follows: Carisolv ${ }^{\mathrm{TM}}$ (Medi Team Dental AB, Savedalen, Sweden) ( $\mathrm{n}=27$ ); Papacárie $^{\circledR}$ (Fórmula \& Ação, São Paulo, Brazil) ( $n=25)$; Manual excavation $(n=22)$.

Calibration: A trained operator performed the clinical interventions. Theoretical and practical training with 17 teeth were performed during a pilot study carried out under the same conditions as the present study. During training, it was emphasized that consistence was more important than the color of the dentine, as a clinical sign of the level of infection. The criteria were discussed exhaustively and good interexaminer agreement was achieved regarding the decision about stopping caries removal. A kappa coefficient of 0.89 was obtained.

Intervention: The sequence of caries removal for each method is described in Table 1. The clinical decision to stop caries removal was based on tactile criteria $^{1,12}$. Caries removal was stopped when the dentine showed slight resistance to excavation and no tug-back sensation was felt when the tip of a blunt explorer was pressed into the dentine. If the dentine was reasonably firm, caries removal was stopped. The color of the dentine was not used as an indicator of the moment to stop excavation. Apart from this clinical criterion, Papacárie ${ }^{\circledast}$ and Carisolv ${ }^{\mathrm{TM}}$ were employed according to the manufacturers' instructions, which establish that caries removal is complete when the gel appears clear and without debris. After caries removal, teeth from the three groups were restored with conventional glass-ionomer cement (Ketac Molar/ 3M-ESPE ${ }^{\mathrm{TM}}$, Monrovia, USA).

Microbiological analysis: Two portions of dentine were collected with sterile excavators $\left(11^{1 / 2}\right.$ Duflex $\left.^{\mathrm{TM}}\right)$ from the middle of the cavity to perform the microbiological analysis of each tooth. The first portion was 
Table 1. Description of the caries removal technique for each group

\begin{tabular}{|c|c|c|}
\hline Carisolv $^{\mathrm{TM} *}$ & Papacarie ${ }^{\circledR *}$ & Manual \\
\hline Periapical X-ray & Periapical X-ray & Periapical X-ray \\
\hline $\begin{array}{l}\text { Isolation with cotton } \\
\text { rolls and saliva ejector }\end{array}$ & $\begin{array}{l}\text { Isolation with cotton } \\
\text { rolls and saliva } \\
\text { ejector }\end{array}$ & $\begin{array}{l}\text { Isolation with cotton } \\
\text { rolls and saliva } \\
\text { ejector }\end{array}$ \\
\hline $\begin{array}{l}\text { Initial sample } \\
\text { collection }\end{array}$ & $\begin{array}{l}\text { Initial sample } \\
\text { collection }\end{array}$ & $\begin{array}{l}\text { Initial sample } \\
\text { collection }\end{array}$ \\
\hline Gel application (30s) & $\begin{array}{c}\text { Gel application } \\
\quad(30-40 s)\end{array}$ & No gel application \\
\hline $\begin{array}{l}\text { Carious dentine } \\
\text { removal with blunt tip } \\
\text { of excavator (Duflex }{ }^{T M} \text { ) }\end{array}$ & $\begin{array}{l}\text { Carious dentine } \\
\text { removal with blunt tip } \\
\text { of excavator (Duflex }{ }^{T M} \text { ) }\end{array}$ & $\begin{array}{l}\text { Carious dentine } \\
\text { removal with active tip } \\
\text { of excavator (Duflex }{ }^{T M} \text { ) }\end{array}$ \\
\hline $\begin{array}{l}\text { Reapplication of } \\
\text { the gel, and caries } \\
\text { removal until the gel } \\
\text { turns clear }\end{array}$ & $\begin{array}{l}\text { Reapplication of } \\
\text { the gel, and caries } \\
\text { removal until the gel } \\
\text { turns clear }\end{array}$ & No gel application \\
\hline $\begin{array}{l}\text { Complete } \\
\text { carious-infected } \\
\text { dentine removal, } \\
\text { checked by a dental } \\
\text { explorer (Duflex }{ }^{T M} \text { ) }\end{array}$ & $\begin{array}{c}\text { Complete } \\
\text { carious-infected } \\
\text { dentine removal, } \\
\text { checked by a dental } \\
\text { explorer (Duflex }{ }^{T M} \text { ) }\end{array}$ & $\begin{array}{c}\text { Complete } \\
\text { carious-infected } \\
\text { dentine removal, } \\
\text { checked by a dental } \\
\text { explorer (Duflex }{ }^{\top M} \text { ) }\end{array}$ \\
\hline $\begin{array}{l}\text { Final sample } \\
\text { collection }\end{array}$ & $\begin{array}{l}\text { Final sample } \\
\text { collection }\end{array}$ & $\begin{array}{c}\text { Final sample } \\
\text { collection }\end{array}$ \\
\hline $\begin{array}{l}\text { Glass-ionomer } \\
\text { cement filling (Ketac } \\
\text { Molar }{ }^{T M} \text { ) }\end{array}$ & $\begin{array}{c}\text { Glass-ionomer } \\
\text { cement filling (Ketac } \\
\text { Molar }^{T M} \text { ) }\end{array}$ & $\begin{array}{c}\text { Glass-ionomer } \\
\text { cement filling (Ketac } \\
\text { Molar }^{\mathrm{TM}} \text { ) }\end{array}$ \\
\hline Follow-up & Follow-up & Follow-up \\
\hline
\end{tabular}

*Following manufacturers' instructions.

collected before caries removal and the second, after caries removal. The active part of the same dentine excavator $\left(11^{1 / 2}\right.$ Duflex $\left.^{\mathrm{TM}}\right)$ used in the first and the second dentine removal procedures was used to measure the dentine samples. Microbiological procedures were based on experiments performed elsewhere ${ }^{15}$. The dentine samples were transferred to glass tubes containing $1 \mathrm{~mL}$ thioglycollate medium used as a carrier and enriched for microbiological detection of mutans streptococci and Lactobacillus spp, after incubation for $6 \mathrm{~h}$ at room temperature. The dentine samples were subsequently stirred vigorously in a vortex blender to produce a suspension. Serial decimal dilutions were prepared in phosphate buffered saline (PBS, 0.01M, pH 7.2). Aliquots of $10 \mu \mathrm{L}$ were inoculated, in triplicate, in selective mediums for mutans streptococci (Mitis-Salivarius Agar - Difco Laboratories, Detroit, MI, containing 20\% sucrose and 0.25 IU bacitracin/mL) and for Lactobacillus spp. (Rogosa Agar, BBL - BD, Basingstoke, United Kingdom). The agar plates were incubated at $37^{\circ} \mathrm{C}$ for $48 \mathrm{~h}$ under an anaerobic atmosphere (Anaerogen, Oxoid Bas-
Table 2. Score description of CFU (colony forming units)

\begin{tabular}{lc}
\hline Score & CFU values \\
\hline 0 & $\leq 3.3 \times 10^{2}$ \\
1 & $3.4 \times 10^{2}-3.3 \times 10^{3}$ \\
2 & $3.4 \times 10^{3}-3.3 \times 10^{4}$ \\
3 & $3.4 \times 10^{4}-3.3 \times 10^{5}$ \\
4 & $\geq 3.4 \times 10^{5}$ \\
\hline
\end{tabular}

ingstoke, United Kingdom), and the colonies were counted and corrected for the dilution factor. The minimum detection count value of colony forming units (CFU) was $3.3 \times 10^{2} \mathrm{CFU} / \mathrm{ml}$, and the results were converted into scores from 0 to 4 (Table 2) to facilitate the description of the results. The microbiological analysis was performed blindly in relation to the caries removal method.

Statistical analysis: Data were analyzed by means of the Kruskal-Wallis and Wilcoxon tests to verify if there were any differences in the reduction of cariogenic flora among the methods used. The statistical level of significance was set at $5 \%$.

\section{Results}

Ten (13.5\%) microbiological samples were excluded due to contamination by fungus or no bacterial growth ( 5 teeth from the Carisolv ${ }^{\mathrm{TM}}$ group and 5 from the Manual group). Table 3 shows the distribution of CFU scores before and after caries removal for the three groups $(n=64)$. CFU scores did not differ significantly among the three groups, neither before nor after caries dentine removal (Kruskal-Wallis test; $p>0.05$ ).

A significant difference was observed in relation to the microbiological scores before and after caries removal for all methods (Wilcoxon test; $p<0.001$ ). CFU scores after caries removal were significantly lower than the initial scores, regardless of the method.

Table 3. Reduction of CFU (colony forming units) scores after treatment with CarisolvTM, Papacárie ${ }^{\circledR}$ and Manual excavation.

\begin{tabular}{lccc}
\hline \multirow{2}{*}{$\begin{array}{l}\text { Reduction of CFU score (Difference } \\
\text { between initial and final score) }\end{array}$} & \multicolumn{3}{c}{ Treatment } \\
\cline { 2 - 4 } & Carisolv $^{\mathrm{TM}}$ & Papacarie $^{\circledR}$ & Manual \\
\hline 4 & 2 & 1 & 5 \\
3 & 7 & 9 & 3 \\
2 & 10 & 5 & 2 \\
1 & 3 & 10 & 7 \\
No reduction & 0 & 0 & 0 \\
Total & 22 & 25 & 17 \\
\hline
\end{tabular}




\section{Discussion}

Chemomechanical methods for caries removal can be expected to display more extensive antimicrobial properties in both carious and clinical sound dentin tissues, by virtue of the presence of substances having antimicrobial properties. In the present study, a significant reduction in the cariogenic microbiota in dentine was observed after caries removal, regardless of the method used. The results of the two chemomechanical methods used were comparable to those obtained after caries removal by manual excavation. Therefore, the two chemomechanical methods evaluated in this study were not more effective in reducing the cariogenic microbiota in dentine carious lesions, in comparison with the manual method.

Previous studies reported similar results with primary teeth, showing that Carisolv $^{\text {TM }}$ did not improve the reduction of cariogenic microbiota (mutans streptococci and Lactobacillus spp.) in dentine caries, compared with manual excavation, ${ }^{14,15}$ or drilling. ${ }^{13,15}$ Conversely, in a clinical study, the reduction of cariogenic flora after caries removal was attributed to the antibacterial properties of Carisolv $^{\text {TM }}$, which has amino acids and sodium hypochlorite in its composition. ${ }^{16}$

Differences in selection criteria, sampling procedures and bacterial culture techniques could explain the controversial results in studies assessing antimicrobial efficacy of the chemomechanical methods..$^{13,14,15,16}$ Some studies used a specific size of sterile bur to collect the dentine samples, ${ }^{12,13,16}$ whereas others used a manual sterile excavator ${ }^{14,15}$ or the specific Carisolv ${ }^{\text {TM }}$ excavator. ${ }^{16}$ In the present study, dentine samples were collected with a sterile excavator $\left(11^{1 / 2} \mathrm{Duflex}^{\mathrm{TM}}\right)$. The use of burs was avoided because of the higher risk of causing accidental pulp exposure. Additionally, their high speed could cause a negative effect on the children's behavior. In addition, some molecular methods, including qPCR, may render different results, because of their sensitivity, especially when dealing with fastidious organisms such as mycobacteria. ${ }^{18}$ Nevertheless, molecular methods may detect DNA of non-viable organisms, as observed in an attempt to detect DNA of Yersinia pestis from skeletons whose patients had deceased from plague in the $14^{\text {th }}$ century. ${ }^{19}$ As reported recently, integrated approaches use both culture methods and molecular detection of other fastidious, difficult-to-grow organisms in dental caries to provide supplementary results for the progression of dental caries. ${ }^{20}$

Unlike this clinical trial, other clinical studies have been conducted under local anesthesia and rubber dam, ${ }^{13,15,16}$ and burs were used on the enamel to facilitate access to the carious dentine. ${ }^{15}$ In the present study, the manufacturers' instructions (Papacárie ${ }^{\circledR}$ and Carisolv ${ }^{\mathrm{TM}}$ ) for chemomechanical caries removal were followed strictly. Therefore, only caries lesions with direct access to the dentine were selected for this clinical trial, and hand instruments were used for undermined enamel. Clinical procedures were carried out with cotton rolls and suction, under proper moisture control.

According to Subramaniam et al., ${ }^{16}$, the reduction in microbiota flora could be attributed to the antibacterial properties of Carisolv ${ }^{\mathrm{TM}}$, which contains amino acids and sodium hypochlorite. During the dentine caries removal in the present clinical trial, it was clear that the proteolytic agents, like the amino acids and hypochlorite in the Carisolv ${ }^{\text {TM }}$ gel, and the papain and chloramines in the Papacárie ${ }^{\circledR}$ gel, facilitated carious dentine excavation. Despite the action of these agents, the chemomechanical methods did not promote antibacterial action in the present study, considering that the Manual group reduced the CFU to a similar extent, even without any chemical agent. The results of the present study showed no significant difference in the ability of the caries removal methods to reduce cariogenic bacteria among the groups.

Several studies have been carried out over the years to make the concept of dentine caries removal more conservative. ${ }^{1,4,6,12,21}$ In pediatric dentistry, chemomechanical methods (Carisolv ${ }^{\mathrm{TM}}$ and Papacárie ${ }^{\circledR}$ ) and ART aim to remove only softened and infected dentine, avoiding over-preparation of the cavity, eliminating pain and discomfort, and reducing both the need for anesthesia and the level of dental anxiety. Satisfactory results with chemomechanical methods have been observed in clinical studies, in regard to preserving tooth structure and promoting patient acceptability. $15,16,22,23,24$

The clinical parameters for the three methods (Papacárie ${ }^{\circledR}$, Carisolv $^{\mathrm{TM}}$ and Manual) were based on resistance to excavation and dentine hardness to indicate that enough caries had been removed ${ }^{12}$. Although the remaining dentine hardness is considered a subjective criterion to indicate adequate caries removal, 
this is the most commonly used method in similar clinical trials. ${ }^{10,13,14,22,24}$ Moreover, it must be borne in mind that, regardless of the method used to excavate caries, there is little evidence to support the concept of complete caries removal. Actually, it is not even possible to remove all the infected dentine..$^{21}$ The relevant bacterial reduction observed in the present study, regardless of the method used to remove caries, indicates that the necrotic and highly infected dentine was removed by excavation. Although the clinical criteria of dental firmness are subjective, it seemed to be enough to guide the operator to decide when to stop removing the caries. In addition, it has been demonstrated that the remaining bacteria left in the bottom of the cavity are not harmful to the dentin-pulp complex and do not lead to further lesion progression or pulp reactions, since the cavity is appropriately sealed with a restorative material. ${ }^{20}$ Prior to the study, good interexaminer agreement was achieved between the operator and a more experienced clinician regarding the moment to stop removing the caries.

Many clinicians still find it hard to accept the concept that leaving infected dentine in the bottom of the cavity is not deleterious, because they were taught to stop cleaning the cavity only when an undoubtedly sound dentine was reached. However, the dentin is invaded by microorganisms very early during the

\section{References}

1. Ericson D, Kidd E, McComb D, Mjör I, Noack MJ. Minimally invasive dentistry concepts and techniques in cariology. Oral Health Prev Dent. 2003;1(1):59-72.

2. Borges BC, Campos GB, da Silveira AD, Lima KC, Pinheiro IV. Efficacy of a pit and fissure sealant in arresting dentin noncavitated caries: a 1-year follow-up, randomized single-blind, controlled clinical trial. Am J Dent. 2010 Dec;23(6):311-6.

3. Borges BC, De Souza Bezerra Araújo RF, Dantas RF, De Araújo Lucena A, De Assunção Pinheiro IV. Efficacy of a non-drilling approach to manage non-cavitated dentin occlusal caries in primary molars: a 12-month randomizd controlled clinical trial. Int J Paediatr Dent. 2012 Jan;22(1):44-51.

4. Banerjee A, Watson TF, Kidd EA. Dentine caries excavation: a review of current clinical techniques. Br Dent J. 2000 May;188(9):476-82.

5. Ricketts DN, Pitts NB. Novel operative treatment options. Monogr Oral Sci. 2009 Jun;21:174-187. caries process and even a so-called complete caries removal does not guarantee complete elimination of the bacteria ${ }^{21}$. After partial caries removal, some bacteria still remain within the affected dentine tissue, but this bacteriological content is compatible with health. ${ }^{12}$ Moreover, caries recurrence cannot be attributed exclusively to the residual bacterial counts in dentine, since other factors may represent a more relevant influence on the recurrence of secondary caries, like marginal failure and presence of gap on remaining restored/sealed carious dentin, leading to leakage and infiltration of bacteria and carbohydrates. ${ }^{14}$ The irrelevance of the remaining carious dentine is accepted, in accordance with the concept that caries progression is driven by the metabolically active biofilm stagnated on the tooth surface, and not by the infected dentine left prior to sealing the cavity. ${ }^{6,21}$

\section{Conclusion}

In accordance with the results obtained in the present study, the reduction in cariogenic microbiota in dentine after caries removal by chemomechanical means was comparable with the reduction by conventional manual excavation. Thus the use of chemomechanical gels does not make caries removal more effective than manual excavation in reducing cariogenic microbiota in the remaining dentine.

6. Bjørndal L, Larsen T. Changes in the cultivable flora in deep carious lesions following a stepwise excavation procedure. Caries Res. 2000 Nov-Dec;34(6):502-8.

7. Frencken JE, Makoni F, Sithole WD, Hackenitz E. Three-year survival of one-surface ART restourations and glass-ionomer sealants in a school oral health programme in Zimbabwe." Caries Res. 1998;32(2):119-26.

8. Ericson D, Zimmerman M, Raber H, Götrick B, Bornstein R, Thorell J. Clinical evaluation of efficacy and safety of a new method for chemomechanical removal of caries. A multicentre study. Caries Res. 1999 May-Jun;33(3):171-7.

9. Bussadori SK, Guedes CC, Bachiega JC, Santis TO, Mota LJ. Clinical and radiographic study of chemical-mechanical removal of caries usig Papacárie: 24 month follow up " J_Clin Pediatr Dent. 2011 Spring;35(3):251-254.

10. Fure S, Lingström P. Evaluation of the chemomechanical removal of dentin caries in vivo with a new modified Carisolv ${ }^{\mathrm{TM}}$ gel. Clin Oral Invest. 2004 Sep;8(3): 139-44. 
11. Ammari MM, Moliterno L. Remoção químico-mecânica da cárie: evidências atuais. Rev Bras Odontol. 2005;62(1/2)125-7.

12. Kidd EA, Joyston-Bechal S, Beighton D. Microbiological validation of assessments of caries activity during cavity preparation. Caries Res. 1993;27(5):402-8.

13. Lager A, Thornqvist E, Ericson D. Cultivatable bacteria in dentin after caries excavation using rose-bur or carisolv. Caries Res. 2003 May-Jun;37(3):206-11.

14. Azrak B, Callaway A, Grundheber A, Stender E, Willershausen B. Comparison of the efficaccy of chemomechanical caries removal (Carisolv) with that of conventional excavation in reducing the cariogenic flora. Int J Paediatr Dent. 2004 May;14(3):182-91.

15. Lima GQ, Oliveira EG, Souza JI, Monteiro Neto V. Comparison of the efficacy of chemomechanical and mechanical methods of caries removal in the reduction of Streptococcus mutans and Lactobacillus spp in carious dentine of primary teeth. J Appl Oral Sci. 2005 Dec;13(4):399-405.

16. Subramaniam P, Babu KL, Neeraja G. Comparison of the antimicrobial efficacy of chemomechanical caries removal (carisolv) with that of conventional drilling in reducing cariogenic flora. J Clin Pediatr Dent. 2008 Spring;32(3):215-9.

17. Needleman I, Worthington H, Moher D, Schulz K, Altman DG. Improving the completeness and transparency of re- ports of randomized trials in oral health: The CONSORT Statement. Am J Dent. 2008 Feb;21(1):7-12.

18. Räsänen NH, Rintala H, Miettinen IT, Torvinen E. Comparison of culture and qPCR methods in detection of mycobacteria from drinking waters. Can J Microbiol. 2013;59:280-286

19. Gilbert MT, Cuccui J, White W, Lynnerup N, Titball RW, Cooper A, Prentice MB. Absence of Yersinia pestis-specific DNA in human teeth from five European excavations of putative plague victims. Microbiology. 2004; 150: 341-354.

20. Nyvad B, Crielaard W, Mira A, Takahashi N, Beighton D. Dental caries from a molecular microbiological perspective. Caries Res. 2013;47: 89-102.

21. Kidd EA. How 'clean' must a cavity be before restoration?. Caries Res. 2004 May-Jun;38(3):305-13.

22. Maragakis GM, Hahn P, Hellwig E. Clinical evaluation of chemomechanical caries removal in primary molars and its acceptance by patients. Caries Res. 2001 May-Jun;35(3):205-10.

23. Nadanovsky P, Cohen Carneiro F, Souza de Mello F. Removal of caries using only hand instruments: a comparison of mechanical and cheo-mechanical methods. Caries Res. 2001 Sep-Oct;35(3):384-9.

24. Kavvadia K, Karaggiani V, Polychronopoulou A, Papagiannouli L. Primary teeth caries removal using the carisolv chemomechanical method: a clinical trial. Pediatr Dent. 2004 Jan-Feb;26(1):23-8. 